\title{
Female Pelvic Vein Embolization: Indications, Techniques, and Outcomes
}

\author{
Anthony James Lopez
}

Received: 22 April 2014/ Accepted: 8 February 2015/Published online: 25 March 2015

(c) The Author(s) 2015. This article is published with open access at Springerlink.com

\begin{abstract}
Until recently, the main indication for pelvic vein embolization (PVE) in women was to treat pelvic venous congestion syndrome (PVC) but increasingly, patients with refluxing pelvic veins associated with leg varicosities are also being treated. A more unusual reason for PVE is to treat pelvic venous malformations, although such lesions may be treated with sclerotherapy alone. Embolotherapy for treating PVC has been performed for many years with several published studies included in this review, whilst an emerging indication for PVE is to treat lower limb varicosities associated with pelvic vein reflux. Neither group, however, has been subjected to an adequate randomized, controlled trial. Consequently, some of the information presented in this review should be considered anecdotal (level III evidence) at this stage, and a satisfactory 'proof' of clinical efficacy remains deficient until higher-level evidence is presented. Furthermore, a wide range of techniques not accepted by all are used, and some standardization will be required based on future mandatory prospective studies. Large studies have also clearly shown an unacceptably high recurrence rate of leg varicose veins following venous surgery. Furthermore, minimally or noninvasive imaging is now revealing that there is a refluxing pelvic venous source in a significant percentage of women with de novo leg varicose veins, and many more with recurrent varicosities. Considering that just over half the world's population is female and a significant number of women not only have pelvic venous reflux, but also have associated leg varicosities, minimally invasive treatment of
\end{abstract}

\footnotetext{
A. J. Lopez $(\bowtie)$

The Imaging Clinic, Thursley Hall, Farnham Lane, Haslemere, Surrey GU27 1HA, UK

e-mail: consultant@ radiologist.co.uk
}

pelvic venous incompetence will become a common procedure.

Keywords Venous intervention - Diagnostic . Embolization/embolotherapy · Pain management . Sclerotherapy · Sedation · Vein · Pain · Pelvic congestion syndrome/chronic pelvic pain - Varices . Varicocele · Varicose veins

\section{Introduction}

Ovarian and other pelvic varices (such as in the distribution of the internal iliac veins) are not an infrequent finding in adult women, and particularly those who have previously had at least one pregnancy associated with a vaginal delivery or at least a significant trial of labour [1]. However, they are also well described in asymptomatic parous women [2].

Traditionally, such varices were diagnosed directly on clinical examination of vulval or perivulvar areas, or indirectly from a symptomatic history supporting the clinical diagnosis of 'pelvic venous congestion syndrome'. However, more recently, it has become apparent that most of these varicosities can only be demonstrated adequately with noninvasive or minimally invasive imaging techniques. Some centres regard catheter venography as the optimum [3, 4] and others, transvaginal [5] or transperineal [6] duplex ultrasound scanning. In the author's experience, transvaginal Doppler has not been widely adopted as it is very much operator dependent and difficult to reproduce and validate, and thus confined to a very few specialist centres. In contrast, venography is widely available, more objectively comparable, and has been used to 'confirm' refluxing pelvic veins suggested on a leg vein Doppler mapping study. 
Pelvic venous incompetence is usually the underlying aetiology in the causation of pelvic varices and has been well known to be manifest as pelvic venous congestion syndrome [7] and usually reflects damage of pelvic vein valves during parturition [8], but it also rarely results from congenital venous stenosis or webs such as in MayThurner syndrome [9], or acquired venous stenosis perhaps associated with iatrogenic or other trauma [10], tumour or deep venous thrombosis [11]. This well-recognized but poorly understood condition presents with a spectrum of symptoms including non-cyclic pelvic and sometimes abdominal pain for greater than six months duration, dyspareunia, dysmenorrhea, haemorrhoids, bladder irritability, and symptoms of irritable bowel syndrome although there are several others [7]. However, the diagnosis can only be made by excluding other causes of chronic pelvic pain such as pelvic inflammatory disease, endometriosis, adenomyosis, fibroids, and prolapse.

Over the last fifteen years, many venous clinics have formally evaluated all patients with Doppler ultrasound evidence of lower limb venous insufficiency and evidence of pelvic venous origin on this leg study, using pelvic venography, transvaginal or transperineal duplex sonography, and identified as many as $15-20 \%$ of patients with lower limb varicosities partly or completely of pelvic origin, reflecting significant pelvic venous incompetence [5]. However, the percentage of such patients rises to up to $30 \%$ [12] if they have recurrent varicose veins whether originally treated by conventional surgery or more contemporary minimally invasive endovenous procedures. Similarly, in Perrin's study of 170 patients, pelvic vein reflux was present in approximately $17 \%$ of patients with recurrent varices after surgery [13]. The relationship between pelvic venous incompetence and both PVC and lower limb varicosities, however, remains intuitive and to some extent empirical clearly, requiring further evidence, and ideally should be subjected to a randomized controlled trial.

\section{Radiological Anatomy}

A detailed understanding of the relevant pelvic venous anatomy including common variants is essential in the minimally invasive management of pelvic venous incompetence using endovenous techniques.

Usually, blood in the left ovarian vein drains into the inferior vena cava (IVC) via the left renal vein, whilst the right ovarian vein is typically a direct tributary into the IVC at a similar level variably between T12 and L2. Occasionally, the left ovarian vein is also a direct tributary into the IVC. Of course, much of this work is based on anatomical dissection, but is gradually being correlated with non-invasive imaging techniques [14].
Valves occur within the main ovarian truncal veins but less so in the internal iliac veins [15]. Ahlberg et al.'s study of 84 post mortem cases [15] suggested that valves were more frequently absent in men than women, and in both sexes, valves were more frequently absent on the left side.

The internal iliac (hypogastric) venous plexus has a far more variable appearance although there are a number of typical patterns. The veins accompany the anterior and posterior divisions of the internal iliac arteries, and it is the tributaries of the anterior division which are of most interest in treating symptomatic pelvic venous reflux. The internal iliac vein typically drains into the common iliac vein by joining the ipsilateral external iliac vein.

In the author's experience, incompetent internal pudendal and broad ligament parametrial branches are most commonly associated with pelvic venous congestion syndrome a priori, whilst incompetent branches of the obturator and circumflex femoral veins are often associated with pelvic venous reflux into vulval (Fig. 1A) or lower limb varicosities (Fig. 1B). Incompetent ovarian (including round ligament) veins may contribute significantly to either clinical manifestation.

Varices are often identified not only in the uterine plexus with dilatation of the arcuate veins of Santorini in the uterine wall, but are also common in the vaginal wall, vulval veins, and periurethral and perianal veins. They are often linked to bladder irritability, urinary frequency, urge incontinence, and haemorrhoids.

It is important to appreciate common and infrequent variants of normal anatomy. For example, the ovarian veins may be duplicated (Fig. 2), or they may drain into visceral branches such as the paravertebral or mesenteric veins [16], and clearly a failure to appreciate this can have disastrous consequences during therapeutic embolotherapy.

Similarly, the obturator vein which normally has two draining tributaries into the anterior division of the internal iliac vein may have two single draining veins into either, or both of, the internal and external iliac veins [17] (Fig. 3).

In the left side of the pelvis, the right common iliac artery may compress the left common iliac vein against the lumbar spine as it crosses it causing venous obstruction. This has been termed May-Thurner syndrome although more recently, the description "nonthrombotic iliac vein lesion" is increasingly used [18] and can involve both right and left iliac veins as well as other venous segments resulting in stasis of blood and the development of blood clots, typically with fibrous spurs.

A well-recognized anomaly is the abdominal 'nutcracker' phenomenon where the left renal vein is compressed by the overarching superior mesenteric artery as it traverses the retroperitoneum anterior to the lumbar spine to drain into the IVC [19] (Fig. 4). However, in the 

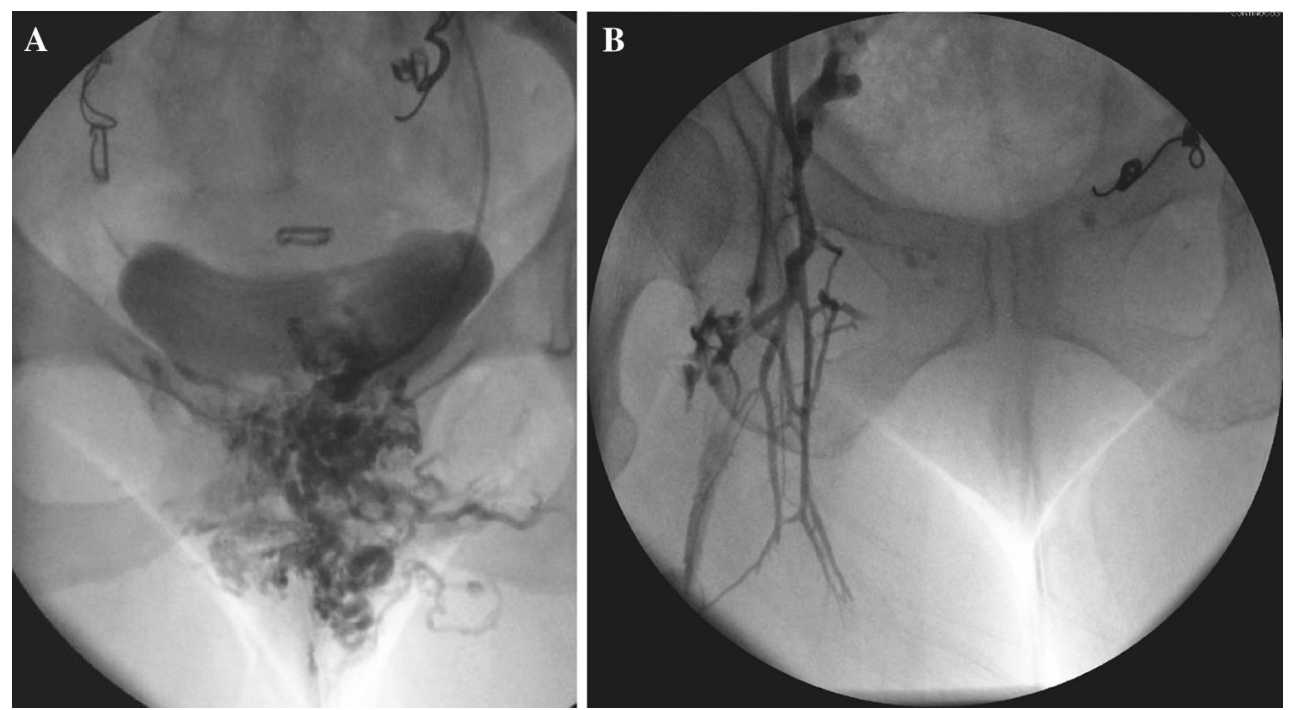

Fig. 1 Refuxing internal iliac venous branches with vulval (A) and lower limb varicosities (B)
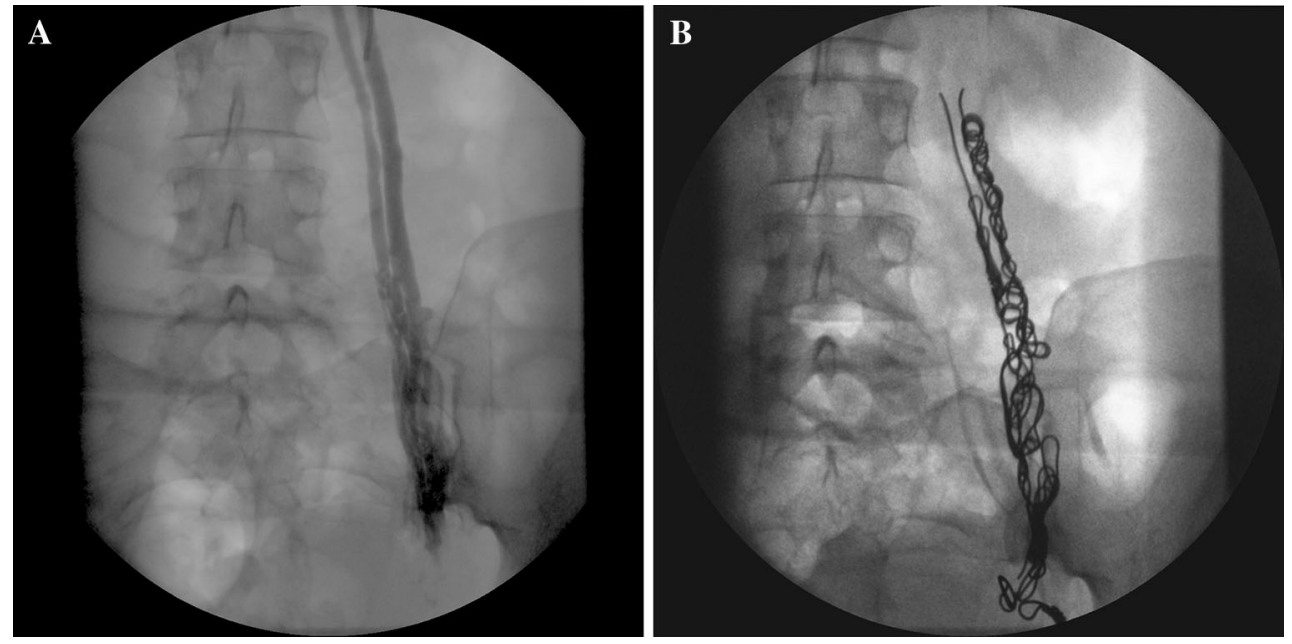

Fig. 2 A and B Duplicated left ovarian vein before and after embolization

author's opinion, this is an overstated cause of a left ovarian varicocele, symptomatic or otherwise.

The diagnosis should be suspected when it is difficult to traverse the left renal vein from the IVC especially if a reverse curve catheter is ultimately required (from a transjugular approach) to catheterize the more distal left renal vein. The appearance of collateral veins from the renal vein on venography or rapid reversal of flow into the ovarian vein (Fig. 4A) favours severe compression. Alternatively, a renocaval pressure gradient of $>4 \mathrm{mmHg}$ is commonly used to diagnose this entity, and some authors have stented the left renal vein for the condition in isolation or following ovarian vein embolization [20]. This may also improve renal venous drainage as in this case, where ovarian vein embolization may result in an elevated renal venous pressure.
As interest in pelvic venous insufficiency associated with pelvic venous reflux has developed alongside technological advances in non- and minimally invasive imaging techniques, attempts have been made to diagnose refluxing veins based on their diameters. For example, a truncal ovarian diameter of greater than $10 \mathrm{~mm}$ at its widest point has been suggested as indicative of reflux [17]. The same authors used other criteria including (1) uterine venous engorgement, (2) moderate or severe engorgement of the ovarian plexus, and (3) filling of the veins across the midline or filling of vulvar or thigh varicosities [17].

Others have used different criteria. For example, Asciutto et al. [21] used the following:

- Varicose reflux towards the ipsi- or contralateral proximal thigh 


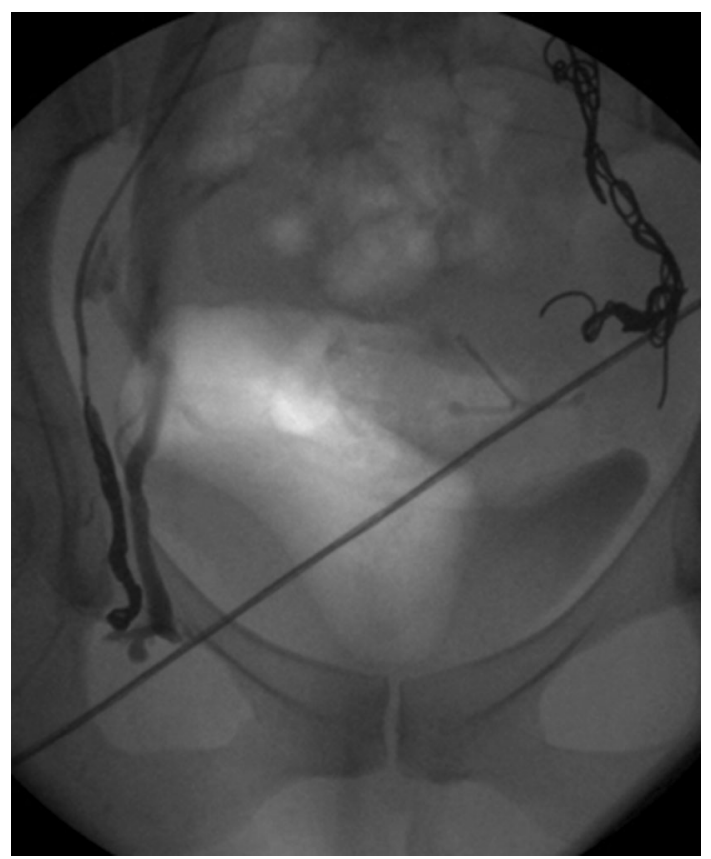

Fig. 3 Obturator veins draining into both internal (catheter in situ) and external iliac veins (right side)

- Visualization of 'reflux' throughout the entire course of the ovarian vein

- Retrograde filling of the main stem of the internal iliac vein and at least one side branch (gluteal, ischial or obturator veins)

- Retrograde filling of contrast medium across the midline.

A number of studies have shown the incidence of refluxing left ovarian and bilateral internal iliac veins as fairly equal and together the commonest pattern [21-26, 27], and although it does not appear to predispose to a particular pattern of symptoms compared to involvement of other pelvic veins, the importance of treating these veins is increasingly being recognized [21, 27].

Typical refluxing vein appearances using these criteria are as follows (Figs. 5A, B and 6A, B).

It is important to remember that large diameter veins do not always reflux and small apparently inconsequential veins may reflux, and it should be recognized that otherwise competent main truncal ovarian veins can be rendered 'functionally' incompetent by large incompetent perirenal or retroperitoneal veins (Fig. 7) where in this case, transvaginal duplex sonography failed to appreciate that this branch is significantly refluxing.

It is not at all uncommon to visualize large retroperitoneal aberrant veins draining into the gonadal veins, and most commonly the ovarian veins (Fig. 8), and these too need to be embolized to eliminate reflux and reduce recurrence.

Although representing less than $0.1 \%$ of patients in most venous practices, male patients with pelvic venous reflux associated with lower limb insufficiency can be treated identically to females with pre-procedural assessment using either transrectal/transperineal duplex sonography, pelvic venography or 'upright MRI' to direct therapeutic embolization.

\section{Technical Considerations}

One of the first documented reports of catheter embolization of incompetent ovarian veins was by Edwards et al. [16] in 1993. Several groups have subsequently reported
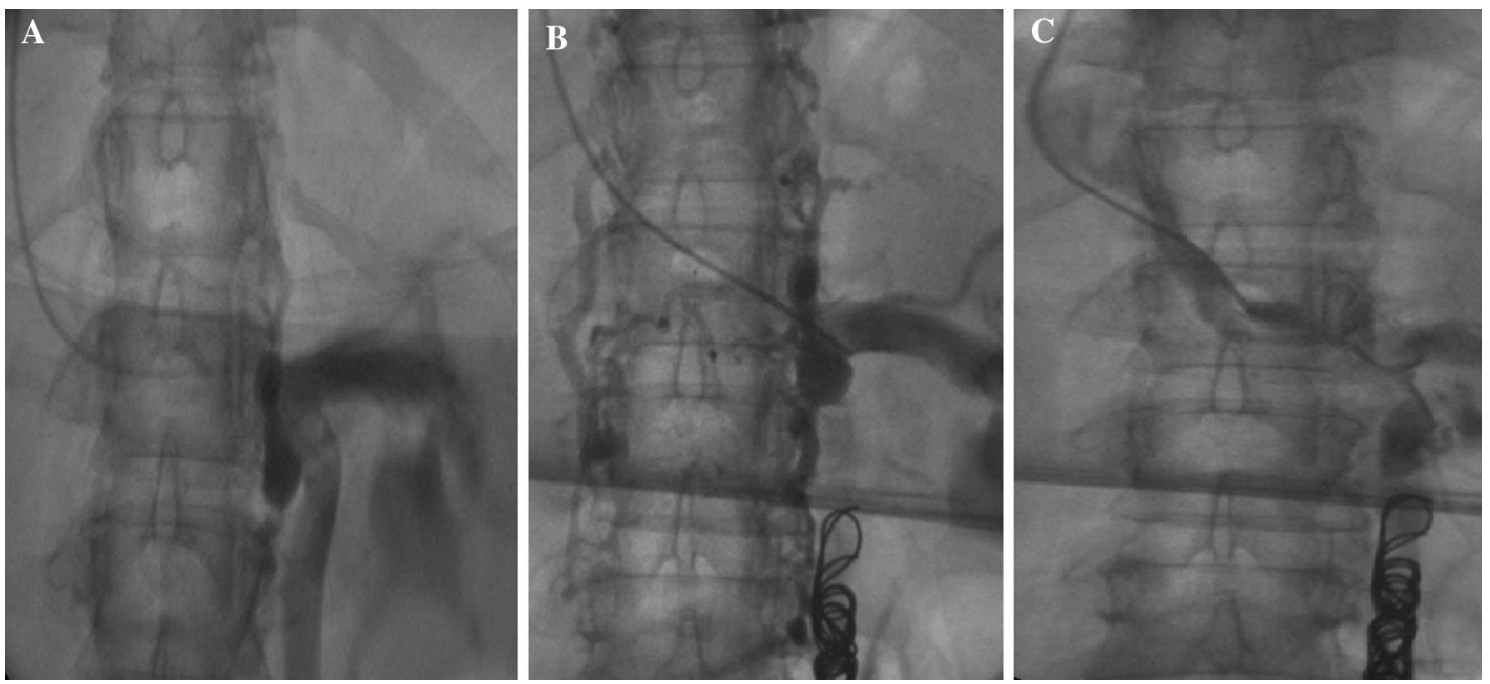

Fig. 4 A-C Abdominal 'nutcracker' phenomenon—despite completely embolizing the enlarged left ovarian vein, the 'compressed' left renal vein still fills poorly on direct injection 


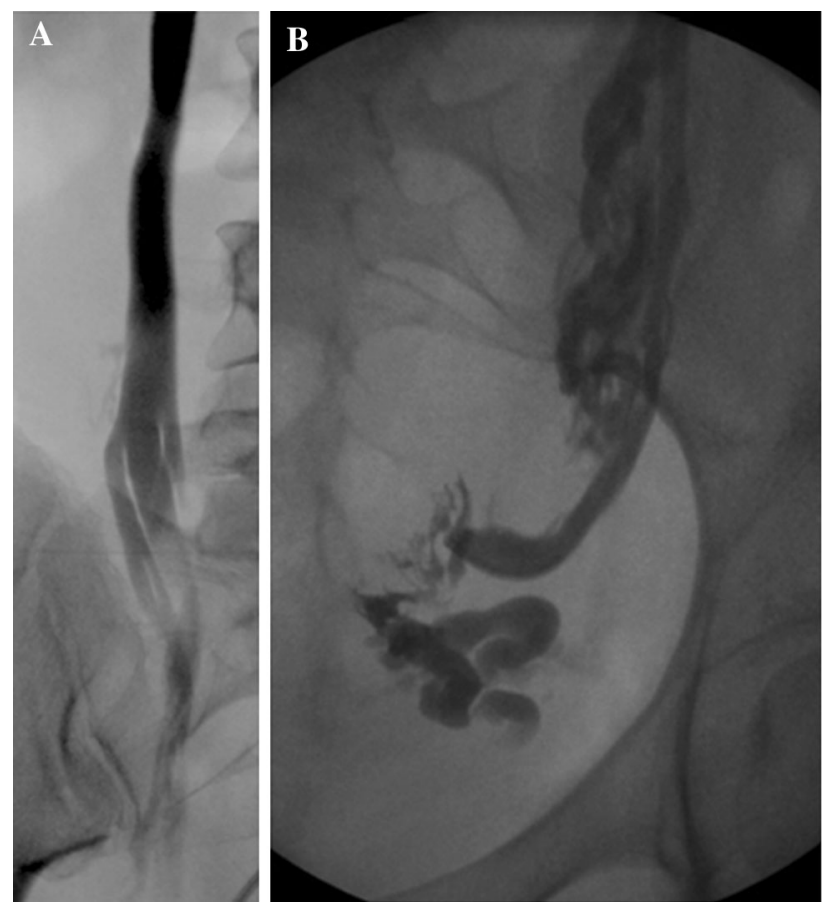

Fig. 5 A and $\mathbf{B}$ Refluxing right and left ovarian veins

series of patients [28-31] but with relatively low numbers and predominantly treating ovarian veins alone. More recently, a number of groups have started to treat the internal iliac veins also $[22,23]$ with the largest published series to date being reported by Kim et al. [24] who treated 131 patients aggressively; Laborda et al. [25] who treated 202 patients; and Monedero et al. [26] who treated 215 patients with recurrent varices after surgery, all using catheter venography as the basis of embolization.

This has now become a routine procedure in many centres, and the author has performed over 1000 such procedures with only very few complications limited to coil migration, minor neck bruising and neck/chest aching [32] on the postprocedural questionnaire delivered at the outpatient clinic review. Specifically, no pneumothorax was recorded although routine chest films were not performed and, whilst pelvic discomfort related to embolized veins is to be expected, it is always without adverse consequences requiring nothing more than simple analgesia for symptomatic relief.

The procedure is essentially the same regardless of the cause of pelvic venous incompetence, treatment typically being directed to the incompetent veins determined by the pre-procedural diagnostic modality used.

A number of approaches to the central visceral abdominal and pelvic veins are available including the femoral, subclavian and brachial veins although in the author's experience, the transjugular or subclavian routes offer the most reliable access to all major relevant pelvic veins from a single puncture site.

The right internal jugular vein is felt by the author to be the most optimum and direct route in his considerable experience. It is highly visible and easy to access under ultrasound guidance, does not typically experience spasm like the brachial vein and affords an antegrade approach, i.e. essentially 'downhill', to all the relevant pelvic veins. There is also less requirement to reform angiographic
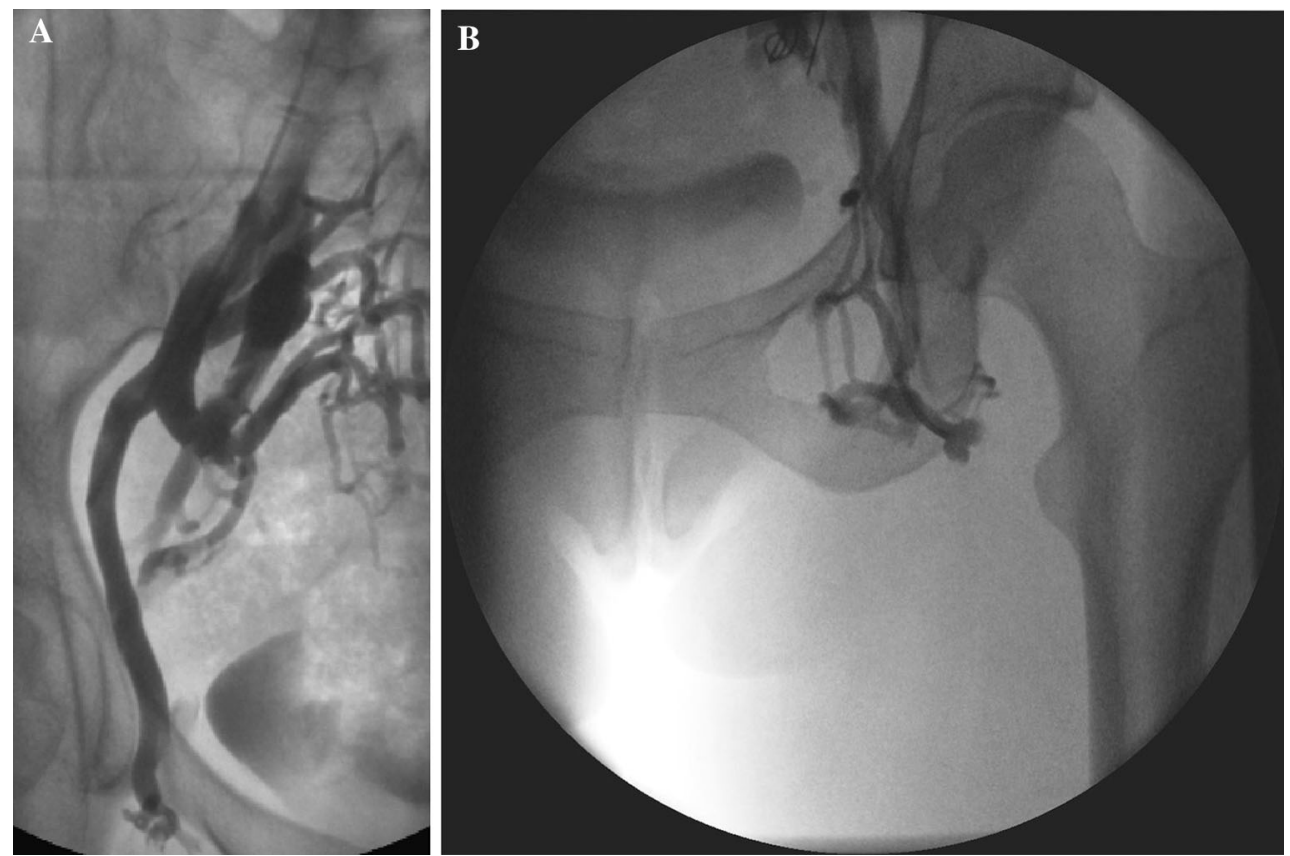

Fig. $6 \mathbf{A}$ and $\mathbf{B}$ Refluxing right and left obturator veins 


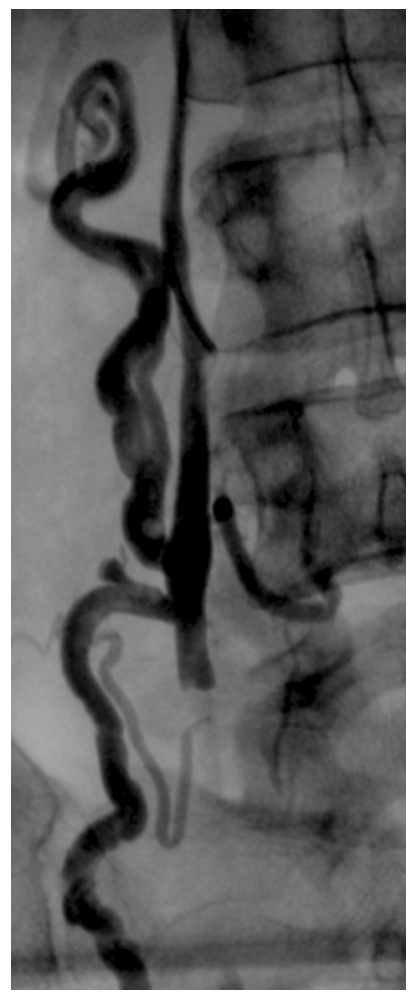

Fig. 7 Non-refuxing 'large' right ovarian vein. Note 'competent' valve along main trunk and aberrant retroperitoneal branches

catheters or use 'reverse curve' catheters such as a 4F Sos omni (Cook Inc, Bloomington, Indianapolis) or 5F Sim 'sidewinder' (Cordis, Miami Lakes, Florida), where there is less control of the embolic agents, as 'turning' a catheter in the opposite direction after pushing a catheter cranially from the groin makes it inherently unstable.

Embolization is typically performed in our institution under mild sedoanalgesia utilizing an opiate and a benzodiazepine together with an antiemetic, although there is no absolute requirement for 'conscious sedation' as the procedure is well tolerated. Typically, the right internal jugular vein (or external if internal unavailable) is directly punctured under ultrasound guidance using local anaesthesia.

'Standard' conventional catheters and guidewires are utilized typically with a 0.035 " 'system' (rather than a 0.018 " microcatheter 'system' placed co-axially), as the target veins are tortuous and dilated easily accommodating standard equipment. Typically, a $6 \mathrm{~F}$ vascular sheath (Cordis, Miami Lakes, Florida), a 5F multipurpose angiographic catheter (Cordis, Miami Lakes, Florida), standard 'moving core' J 0.035" guidewire and an angled hydrophilic wire (Radiofocus, Terumo, Europe) are all that are required to complete a case in usually less than $45 \mathrm{~min}$ for up to four pelvic truncal veins.

Occasionally, a reverse curve catheter such as a $5 \mathrm{~F} \mathrm{Sim}$ catheter (Cordis, Miami Lakes, Florida) reformed at the
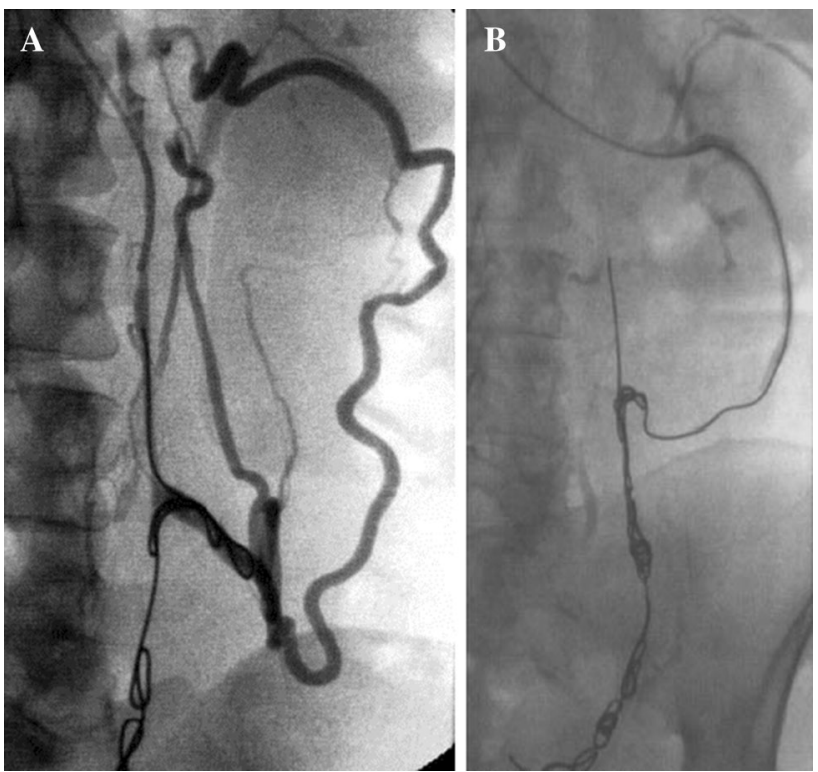

Fig. 8 A and B Aberrant retroperitoneal veins before and after embolization

common iliac venous confluence may be useful to catheterize a spastic or 'difficult' left renal vein (e.g. 'nutcracker' syndrome) in order to superselectively catheterize the left ovarian vein (Fig. 4), prior to reverting to a conventional catheter.

Although only a $5 \mathrm{~F}$ catheter is required for embolization, it is important to remember that a $6 \mathrm{~F}$ sheath will be necessary to enable a misplaced or displaced coil to be retrieved using an Amplatz Goose Neck snare (ev3 Inc, North Plymouth, Minnesota) or other retrieval device.

In contrast to conventional 'open' or laparoscopic surgical techniques, endovenous procedures use a minimally invasive approach to occlude and ultimately ablate refluxing veins [33]. However, physical media such as extreme heat (e.g. radiofrequency, laser, steam) used in treating refluxing 'peripheral' veins are inadvisable for use in the abdomen or pelvis given the proximity of visceral structures such as bowel and ureter, which may be irreversibly damaged.

The commonest embolic agents utilized are platinum embolization coils, foam, glue and liquid sclerosants [e.g. Polidocanol, $3 \%$ sodium tetradecyl sulphate (STS)]. Platinum coils are MRI-compatible up to $1.5 \mathrm{~T}$, associated with little artefact on MRI (although considerably more on CT) and are not detected by an airport scanner which would be a nuisance to the patient and the airport agency. However, newer coils are being developed which also show little or no artefact on CT scanning.

These agents may be used in isolation or together. Indeed recently, STS has been used in association with a 

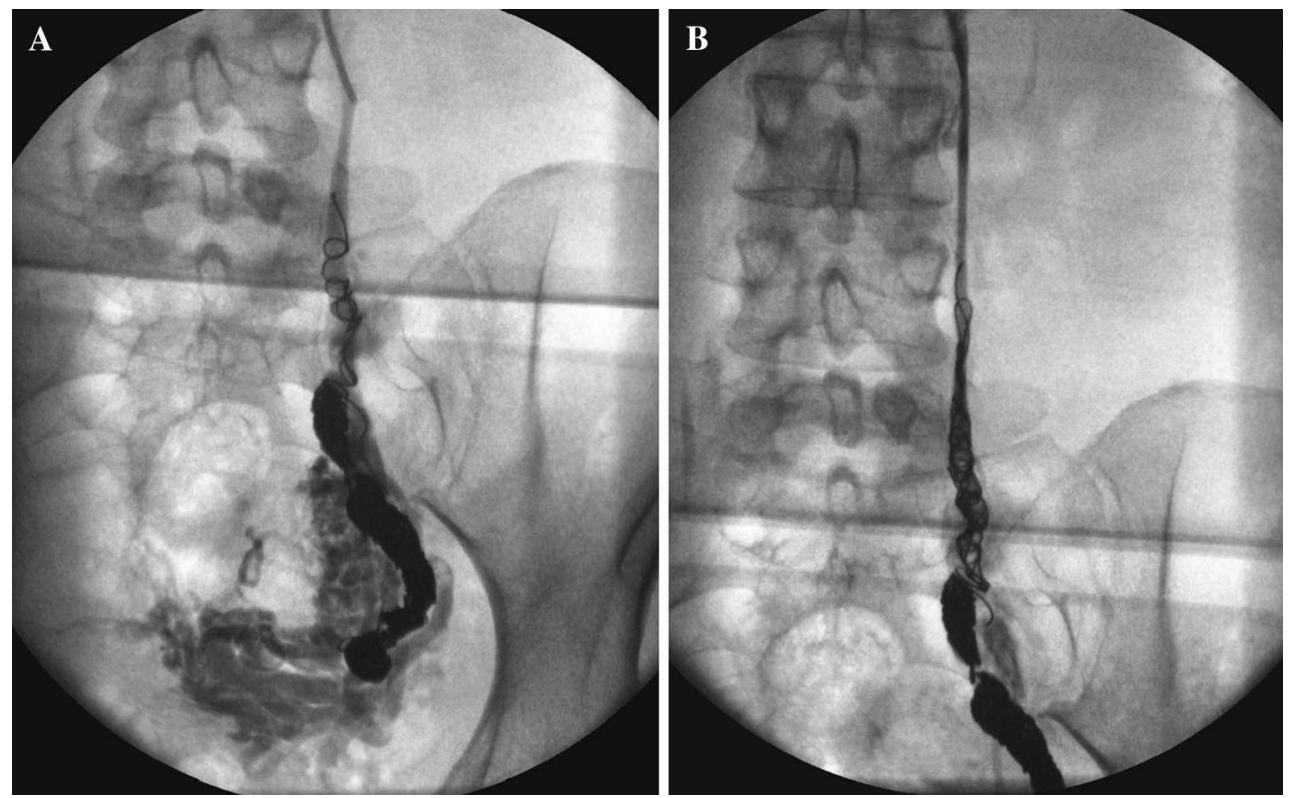

Fig. 9 Persisting ovarian vein reflux following incomplete coil embolization (A) re-treated with 'distal' foam sclerotherapy and 'completion' coil embolization $(\mathbf{B})$

mechanical device used to disrupt the endothelium in the Clarivein system [34] and could potentially be used in pelvic veins, although compression of the ablated vein is integral to its efficacy and clearly this is difficult for pelvic veins. Similarly, glue used either alone or in the Sapheon system [35] could potentially be adopted for use in treating pelvic venous incompetence. However, regardless of the injurious agent used, it is often recommended that a foreign body be left in situ to obviate recanalization, and embolization coils are used by many authors to achieve this. Until more work has been completed and greater long-term outcomes assessed, this potentially makes use of the two latter systems financially unviable for now. Regardless of the agent used, higher-quality evidence in the form of properly conducted randomized controlled studies using a variety of currently available embolics and/or sclerosants is essential in progressing our understanding in this developing field, and these remain lacking.

In our institution, Spirale platinum embolization coils measuring between 8 and $16 \mathrm{~mm}$ in unconstrained diameters (BALT Extrusion, Montmorency, France) were initially used. More recently, 8-12-mm diameter coils 'fibred' with synthetic dacron (Cook Inc, Bloomington, Indianapolis), rather than plain non-fibred coils have been utilized as they achieve more rapid occlusion with fewer coils required, offer easier retrievability if misplaced enabling a lower procedural time and reduced exposure to ionizing radiation. Detachable coils may be particularly useful for the inexperienced operator embolizing in particular, the internal iliac branches and most proximal ovarian veins.
Techniques for coil deployment vary. In contrast to arterial embolization, where tight packing of coils may be advantageous to occlude flow at arterial pressure, it is the author's opinion that a foreign body of appropriate size along near the entire course of the target vessel is all that is required in veins where flow is slow, and thrombosis almost inevitable. Furthermore, densely packing coils in these very long venous segments would be prohibitively expensive, as would the use of Amplatzer vascular plugs (AGA Medical Corporation, North Plymouth, Minnesota).

A fibred platinum coil is progressively 'unwound' along the vessel to achieve complete occlusion. The author feels it important to embolize the entire length of the incompetent vessels including their larger truncal draining tributaries to prevent new collateralization. Although there is no substantial evidence to support this, in the author's experience, 'failed' interventions subsequently referred to a specialist unit are typically shown to have inadequate 'coverage' by coils (Fig. 9), and other experienced operators have adopted a similar strategy [24]. The process may be hastened by oversizing the coil diameter to vessel size and by instilling foam or a liquid embolic alongside or between coils.

Alternatively foam can be administered by free hand injection, or 'controlled' by using a balloon occlusion angiographic catheter (Fig. 10) in both cases by 'pre-filling' the catheter and target vein with iodinated contrast and injecting the foam under modest constant positive pressure to simply displace the contrast from the distal target vessel ensuring complete vessel coverage and minimal reflux. In this respect, it is best to use a $\mathrm{O}_{2} / \mathrm{CO}_{2}$ mixture with $3 \%$ 
sodium tetradecyl sulphate in a 5:2 mixture [36] avoiding room air (which contains $80 \%$ nitrogen increasing the theoretical risk of stroke) in the Trendelenburg position.

Foam is particularly good for treating the smallest 'peripheral' vulval and haemorrhoidal veins (Fig. 11).

The rich venous plexus sometimes allows for contralateral catheterization and embolization, e.g. embolization of the right ovarian vein from the left ovarian vein (Fig. 12) or vice versa and embolization of the left internal iliac gonadal venous branches from its counterpart or vice versa (Fig. 13).

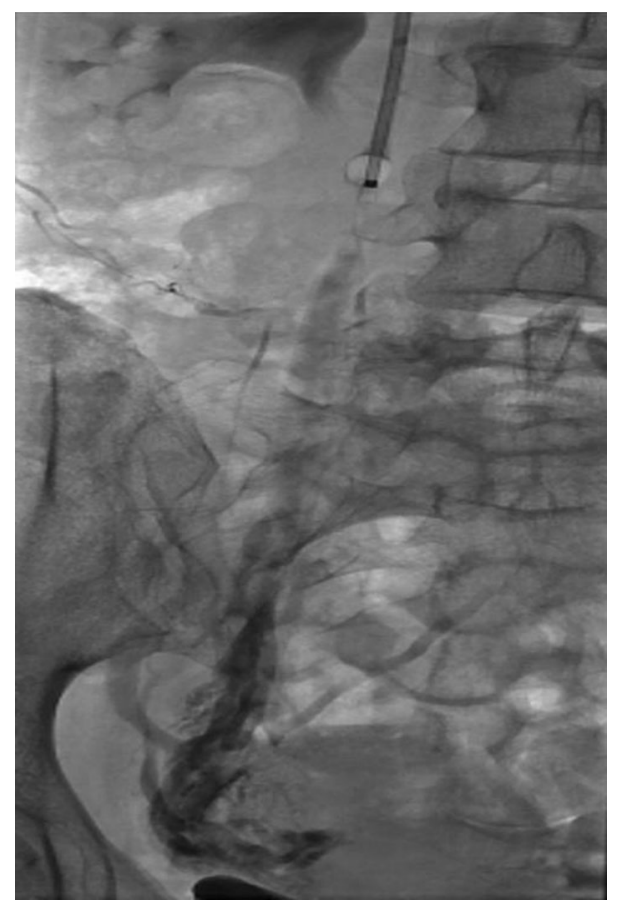

Fig. 10 Foam sclerotherapy of right ovarian vein
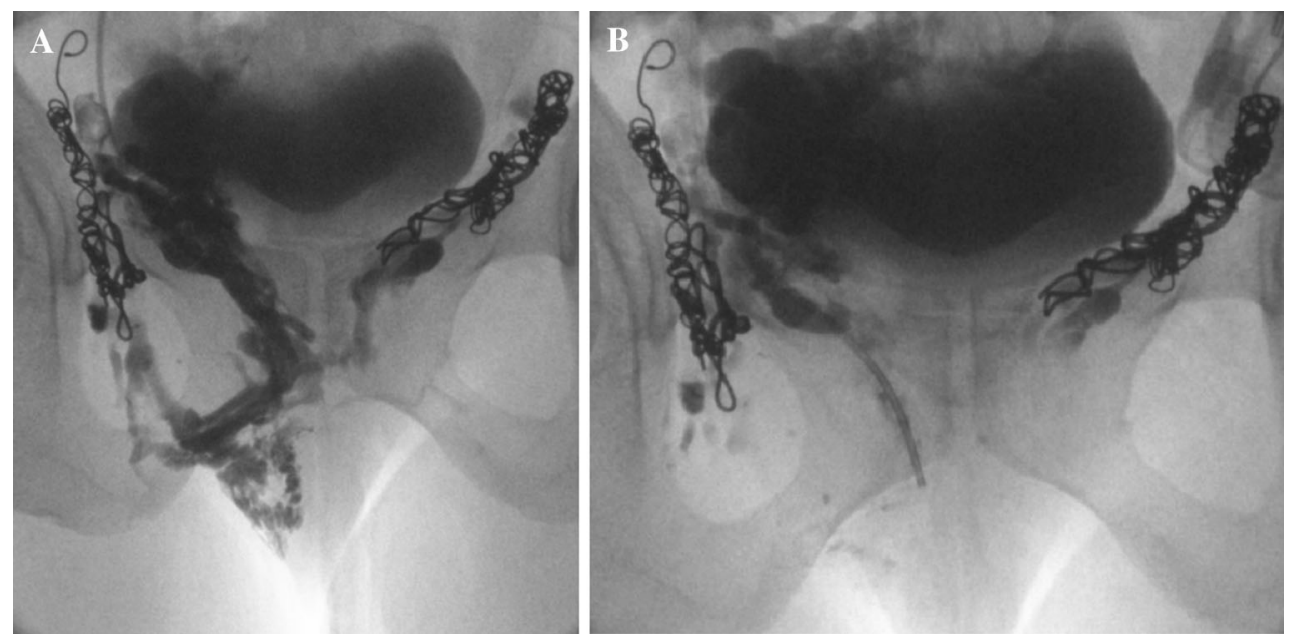

For pelvic venous congestion, it is usual to catheterize refluxing pudendal or broad ligament branches (Fig. 14).

Patients are usually able to leave the hospital or clinic as soon as they have recovered from the sedation (if administered) and would expect to be discharged within 1-2 h. A consistent finding is pelvic aching and occasional discomfort at the needle puncture site, and can usually be successfully managed with a non-steroidal anti-inflammatory drug with only very rarely a requirement for stronger medication.
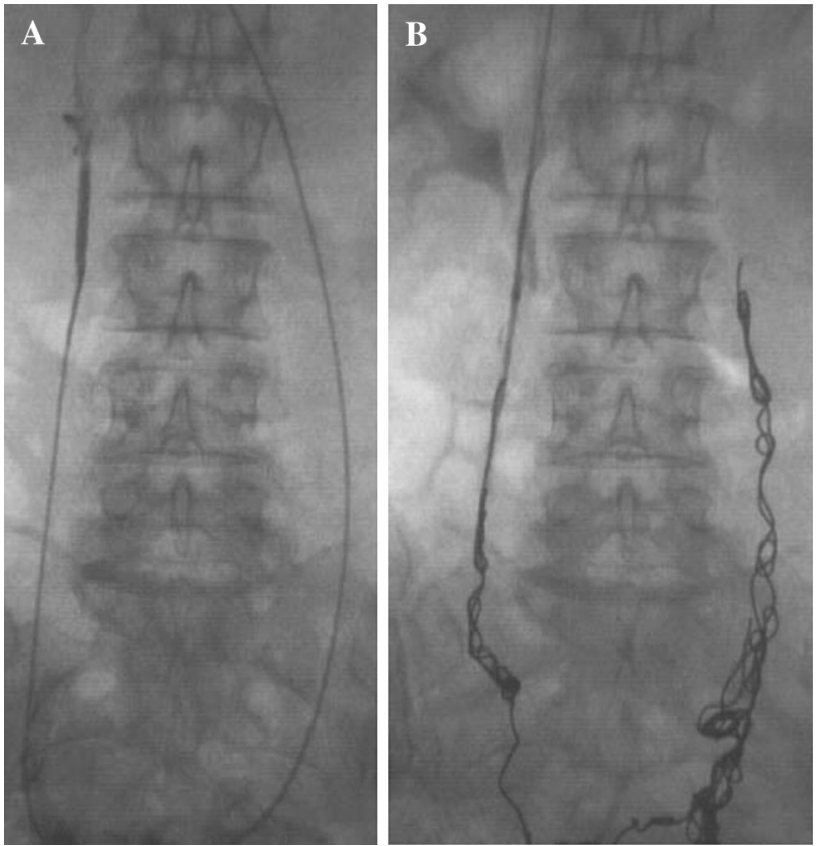

Fig. 12 A and B Cross embolization of right ovarian vein from left vein

Fig. 11 A and B Vulval varices treated with foam sclerotherapy and coil embolization 

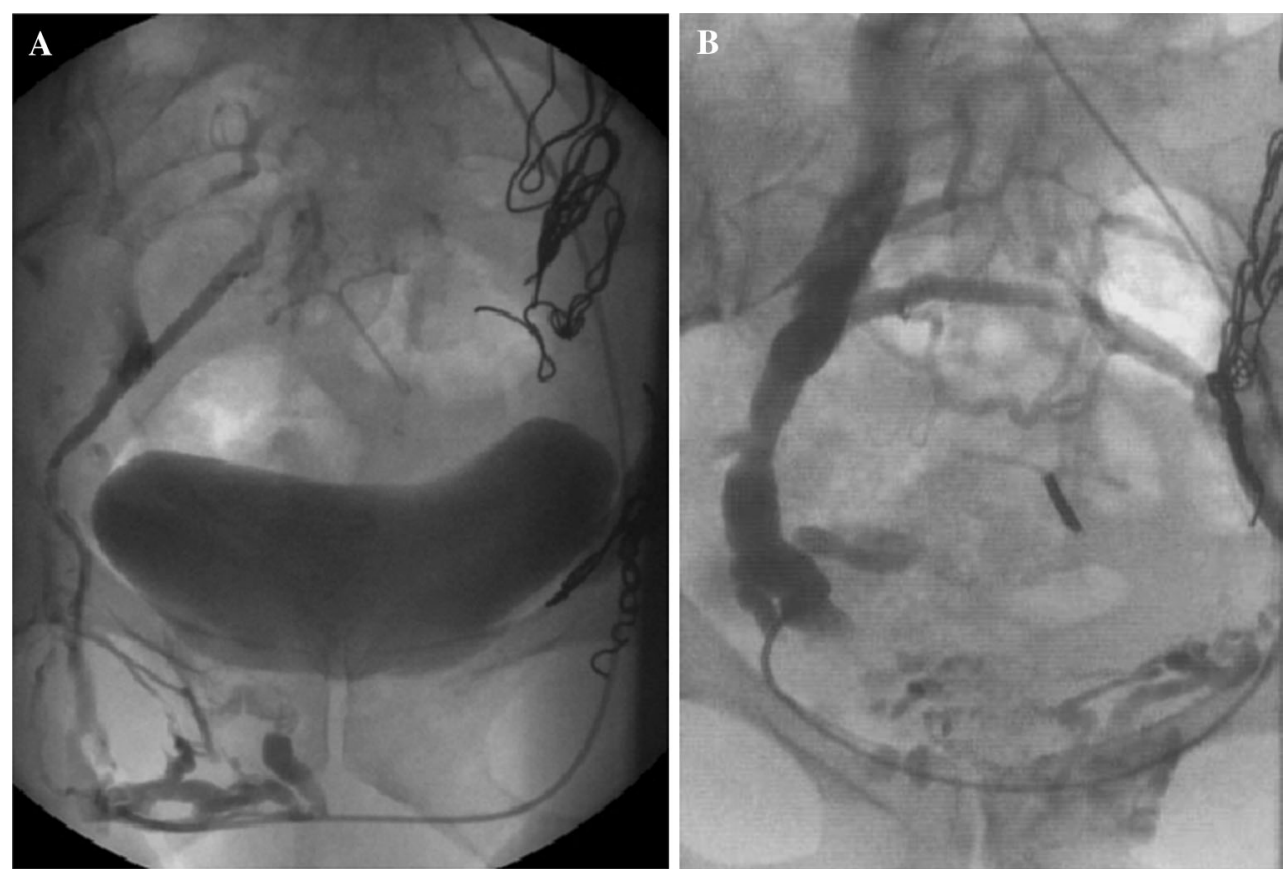

Fig. 13 A and B Cross embolization of right vulval veins from left internal iliac vein

Fig. 14 Pudendal and broad ligament venous embolization
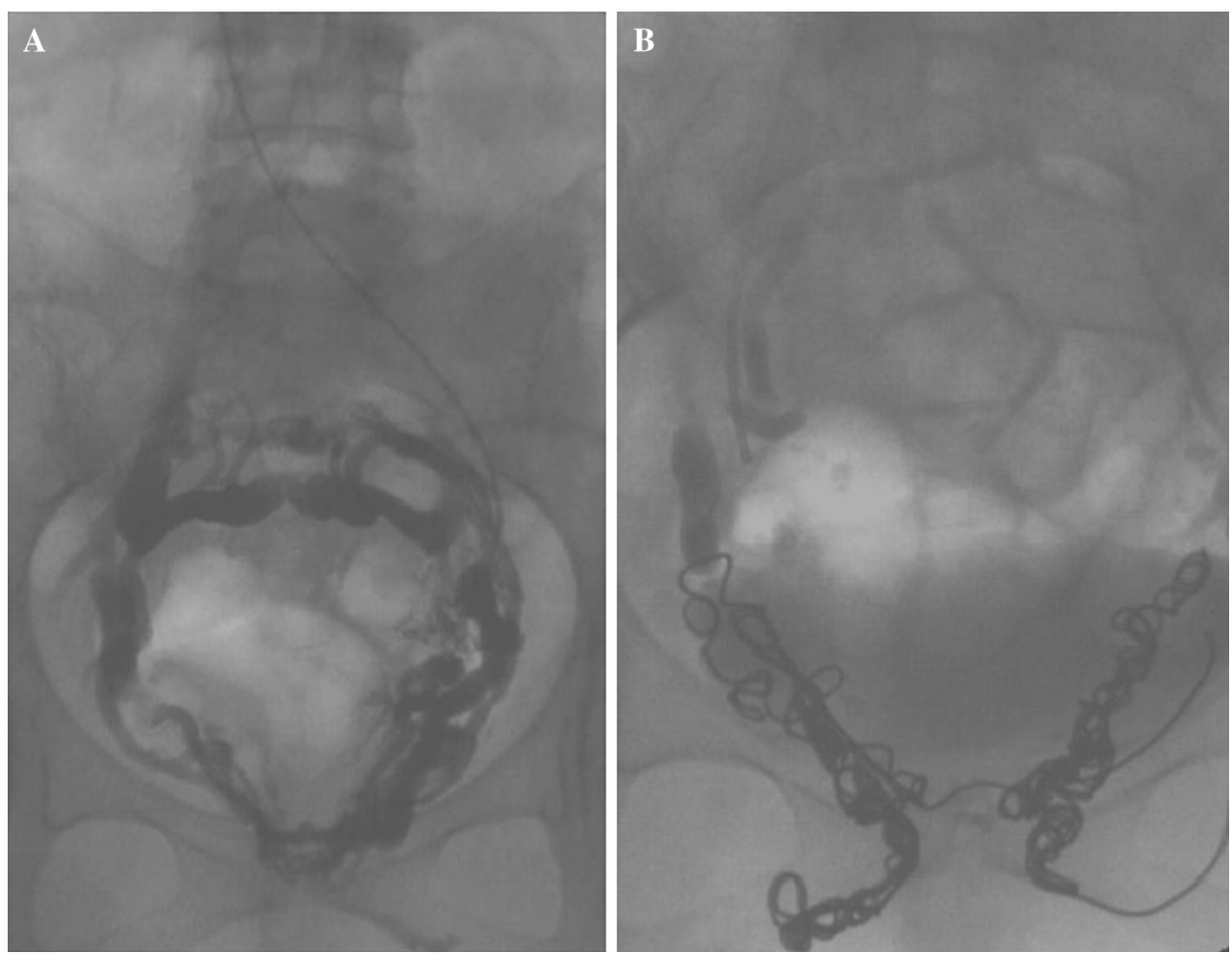

Immediately following embolization, the patient may experience mild-to-moderate discomfort for up to 5 days (but often shorter and rarely longer), and this typically responds rapidly to non-steroidal anti-inflammatory medication. In the author's experience, there is never a requirement for patient-controlled analgesia (PCA).

After approximately 6 weeks, all patients have a followup Doppler ultrasound scan. If reflux is completely 

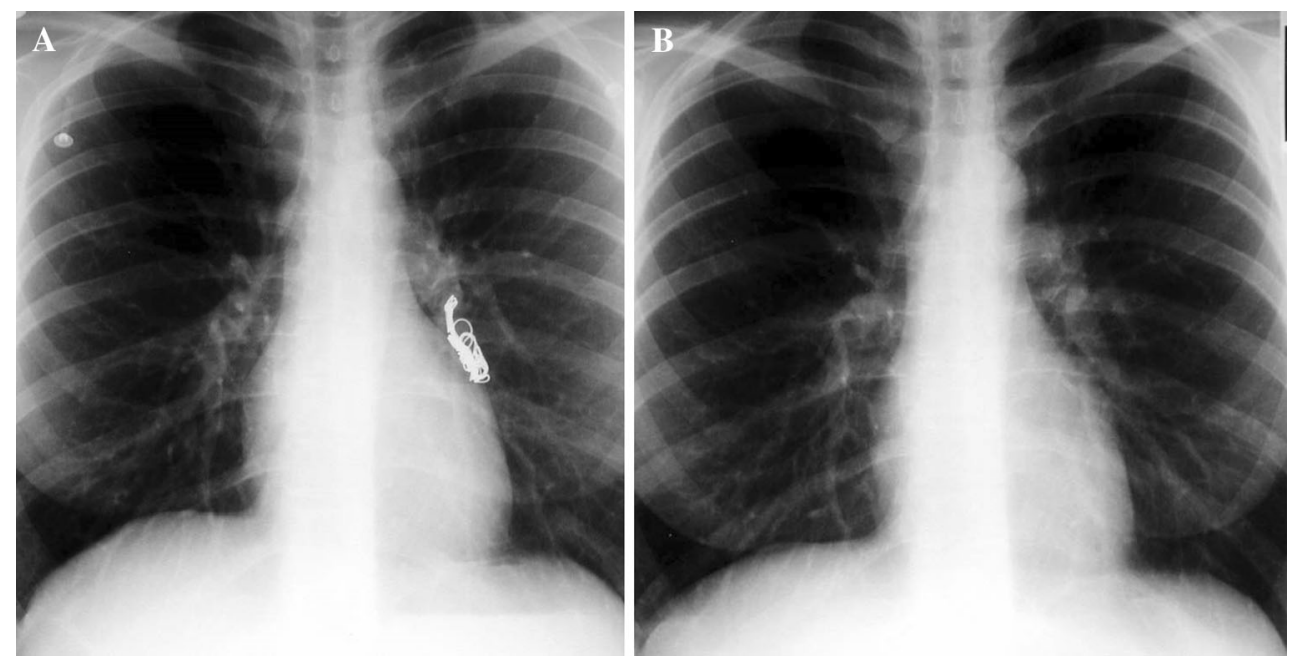

Fig. 15 A and B Inadvertent pulmonary coil embolization (before and after removal)

eliminated or there is very modest 'trickle' reflux, the patient is booked for a definitive endovenous leg vein procedure, e.g. laser treatment (EVLT), radiofrequency ablation (VNUS), or discharged if treated for PVC.

If more substantial persisting or new reflux is demonstrated, localized transcutaneous pelvic foam sclerotherapy can be performed [7] as foam is now less likely to pass cranially into the 'central' veins in significant volumes as the 'back door' to previously identified refluxing veins (but not necessarily new sources) has been virtually closed by pelvic truncal vein occlusion. However, if there is more substantial reflux perhaps through 'undertreatment', or new refluxing veins have opened up (more likely if the patient has an intervening pregnancy), further pelvic embolization may be indicated.

\section{Radiation Protection and Dosimetry}

It is a fundamental principle to limit the patient and staff to as low a dose of ionizing radiation as is reasonably achievable, and it is mandatory to ensure that any benefit conferred by the technique outweighs the small but defined risk associated with the stochastic effects of ionizing radiation

Modern interventional fluoroscopy equipment intensifies the image and uses a relatively low dose of radiation. The dose can be kept to a minimum using low milliamperage (mA) fluoroscopic screening and carefully controlling screening times. This allows perfectly adequate pictures for guidance during treatment but not "ultrasharp" imaging, which is perfectly acceptable, as a balance needs to be achieved. An analogy would be to use a 3 megapixel digital camera providing very affordable yet perfectly satisfactory pictures compared to a markedly expensive 15 megapixel camera producing sharper images!

The dose can be further reduced by limiting the exposure of body area to ionizing radiation with collimators ('coning'), and minimizing the distance between the anode source of radiation and the patient. Clearly, the fewer the veins to be treated, the slimmer the patient and the less the complexity of the anatomy, the lower the radiation dose. Also, the more experienced the staff, the lower the procedure time and therefore the dose. In our institution, medical physicists have calculated the radiation dose during the procedure by measuring the 'dose area product' (DAP) and used the Monte Carlo software to yield an "effective dose". The mean of these measurements (considering the number of veins embolized and given the degree of difficulty varies between patients) is $5200 \mathrm{cGy} / \mathrm{cm}^{2}$ which converts to an effective dose of approximately $6 \mathrm{mSv}$.

What does this mean in 'real' terms? This is equivalent to a CT scan of the abdomen and pelvis using a modern 128 multislice CT scanner at the same hospital. Alternatively, it equates to 3 years of 'natural' background radiation-we are all exposed to background radiation from the surroundings including the sun-(or 1 year of background radiation in some parts of the West of England, e.g. Cornwall). For UK patients, an alternative equivalent would be a return flight to Paris. The conversion is $0.0011 \mathrm{mSv}$ per $\mathrm{cGycm}^{2}$, i.e. multiply the DAP by 0.0011 to get the effective dose (NB it will vary with the size of the patient and the software assumes rectangular collimation rather than the near circular image intensifier field). 


\section{Complications}

Complications are exceedingly rare with meticulous attention to the initial venous puncture and embolization technique. 'Immediate' complications include:

- Those related to drug administration, e.g. narcosis, sedation or rarely hypersensitivity, for example to iodinated contrast (reported in less than $1 \%$ of patients with non-ionic contrast) [37].

- Venous puncture related, e.g. haematoma, pneumothorax (for venous catheterization via a neck vein)

- Embolization of non-target vessels, i.e. coil misplacement, e.g. left ovarian vein involving left renal vein, obturator or circumflex coil protruding into left external iliac or common femoral vein [38]. Caution is advised with liquid embolic agents as communications have been shown to exist between the ovarian veins and paravertebral veins and specifically between the left ovarian vein and splenic, ureteric and inferior mesenteric veins [16, 39].

- Stroke related to paradoxical emboli from coil migration or uncontrolled foam (most likely when using 'room air')

Delayed complications can include

- Enlarging pneumothorax, initially asymptomatic

- Coil migration-typically a post-procedural event, e.g. pulmonary embolization of coils (e.g. Fig. 15).

Such displaced and misplaced coils can be snared and retrieved relatively easily by means of conventional minimally invasive interventional radiology equipment and well-established techniques again using either the same jugular access or additional femoral venous access.

There is very little evidence to suggest that pelvic embolization is associated with an adverse effect on fertility associated with reduced ovarian 'function' [39] but this remains unknown. Indeed, although patients are advised to undergo the procedure when their family is complete, several patients have become pregnant and subsequently undergone successful confinement.

\section{Outcomes}

Since Edward's original case report of bilateral ovarian vein embolization in 1993 [16] to relieve pelvic pain, numerous studies have been reported initially with embolization of ovarian veins alone in relatively small numbers using coils [23, 40-42] or sclerosant alone [43] and subsequently of ovarian and internal iliac veins often in larger series using coils [21, 24], glue [25], sclerosant and coils together $[4,29-32]$. The problem remains a lack of standardization of clinical assessment, imaging and treatment methods for two main conditions that are still not fully accepted, and the absence of consistently high level evidence by way of randomized control trial (RCT).

The earlier studies predominantly included women with PVC including pelvic pain assessed using a questionnaire or visual analogue scale (VAS). Partial or complete relief of chronic pelvic pain was achieved in up to $80 \%$ of patients $[29,30]$ with relatively small patient numbers, whilst more recent studies treating both ovarian and internal iliac veins claim relief in up to $94 \%$ in larger patient series [25]. Others have similarly had relatively large patient numbers but treated just ovarian vein reflux, such as Kwon who reports $82 \%$ symptom improvement in 67 patients followed for up to 6 years from a review of medical records and telephone interviews [44]. Maleux et al., with a technical success of $98 \%$ in 41 patients, followed up patients by questionnaire, reporting "total relief of symptoms in $59 \%$ of patients with those undergoing unilateral compared to bilateral ovarian vein embolization [31].

Venbrux's group [39] achieved $100 \%$ technical success in 56 patients and recorded some degree of improvement (with a reduction of at least one point from baseline of the VAS score between baseline and follow up). Kim adopted a similarly aggressive approach embolizing all incompetent ovarian and internal iliac venous branches to eliminate all reflux [24]. This group evaluated the response of 127 patients with PVC over a 27-63-month duration again using questionnaires and a VAS, recording an improvement in $83 \%$ over this relatively longer term follow up compared to previous studies. Furthermore, conservative management of patients with isolated internal iliac vein reflux did not resolve symptoms [21]. However, some reflux may occur in healthy subjects as valves are only found in approximately $10 \%$ of internal iliac veins and their tributaries [45] and such as an aggressive strategy remains a matter of opinion.

Chung's 2003 study [46] compared the efficacy of pelvic vein embolization with hysterectomy (with either unilateral or bilateral oophorectomy) for PVC associated non-cyclical chronic pelvic pain. Over a period of 4 years, 164 women were diagnosed with PVC "confirmed" with diagnostic laparoscopy and venography of ovarian and internal iliac veins. Of these patients, 118 failed to respond to medical therapy alone, and were recruited for randomization to embolotherapy and hysterectomy with either unilateral or bilateral oophorectomy. Pain was assessed with a VAS, and life changes in the previous 12 months analysed with a stress-scoring questionnaire used to subclassify into three groups. All patients underwent transfemoral venography, and Beard et al.'s pelvic venogram scoring system was used [47] in a modified form. Ovarian and internal iliac veins were variably embolized and embolotherapy was found to be significantly more effective than the other treatment arms in 
reducing pelvic pain, especially in patients with lower stress scores. One difficulty with this study is that it uses an infrequently adopted pelvic venous scoring system and a nonstandardized protocol for coil placement was utilized. It is telling that it remains one of the only published RCTs to date in treating PVC syndrome with embolotherapy.

Later studies have concentrated on the more frequently occurring recurrent lower limb varicose vein patient group with either clinical assessment such as a decrease in venous clinical severity score [4] or using minimally invasive imaging such as transvaginal Doppler sonography [27].

Indeed, one of the largest series using follow-up Doppler assessment by just two vascular sonographers records well over $95 \%$ success in ablating refluxing veins demonstrated pre-procedure following embolization by a single operator [32].

Monedero et al [26] evaluated 215 patients with recurrent varices after surgery (REVAS) with transvaginal Doppler sonography and selective pelvic venography. This group treated incompetent ovarian and internal iliac veins as well as collateral branches, with embolization using variably coils and foam using a transfemoral or basilic vein approach. Total relief of pelvic pain accompanied by reduced lower extremity venous stasis clinically was reported in $50 \%$ of patients, and partial relief in $40 \%$. This group reported that the underlying cause of REVAS was partly due to blood leaking from the pelvis into the lower extremity.

A similarly large study by Ratnam et al. also looked specifically at the role of pelvic venous embolization in the management of lower limb varicosities [27]. 218 patients with pelvic venous incompetence as either a contributing factor or sole cause of varicose leg veins diagnosed exclusively with transvaginal duplex sonography were treated exclusively with platinum coil embolization. The study demonstrated a $100 \%$ technical success rate using exclusively a transjugular approach with one reported coil misplacement without adverse effect [38] and two cases of pulmonary embolization of migrated coils, only one of which was symptomatic with the coils retrieved successfully using an endovenous approach.

A considerably smaller but more recent study also suggested that REVAS is reduced following embolization of incompetent pelvic veins and is particularly efficacious if patients are also experiencing symptoms of PVC [4] which often improve.

\section{Specific Considerations Managing Pelvic Venous Congestion Compared to Leg Varicosities of Pelvic Venous Origin}

Clinically, it is clear that the spectrum of symptoms and physical signs in the two main patient groups with pelvic venous incompetence, i.e. PVC syndrome and lower limb varicose veins a priori or presenting as REVAS, is wide with considerable overlap. Radiologically, they are difficult to separate.

Empirically, investigators may think that PVC would be most often associated with incompetent ovarian, pudendal and other parametrial branches, whilst pelvic varices would be likely associated with refluxing obturator, circumflex and round ligament branches. However, the body of evidence suggests that it is not as simple as that. Scultetus described three clinical presentations in an overview of 'female pelvic venous syndrome'-vulval varices without PVC symptoms, medial and posterior thigh varicosities associated with ovarian venous incompetence, and gluteal varicosities with vulval varices usually caused by internal iliac vein incompetence [48]. Experienced operators agree that the anatomy is so variable and pelvic venous incompetence so complex, and therefore, recommendations for treatment cannot be given [49].

\section{Discussion}

For over 20 years, pelvic vein embolization (PVE) and most commonly ovarian vein embolization, has been performed principally for pelvic venous congestion syndrome (PVC). Evidence remains poor for its efficacy, and although initially anecdotal by way of case reports and small series, data is accumulating in larger series. There remains, however, a lack of robust evidence of its effectiveness, and this partly reflects the challenges of actually making the diagnosis clinically and radiologically, as well as the difficulty in assessing outcome. For PVC, symptomatic response is usually subjective but visual analogue scales (or variations thereof) have most often been used to attempt to identify a more objective outcome.

It may be argued that PVE is an established procedure that has been awaiting a significant clinical problem, and most interventional radiology suites do not perform the procedure in significant numbers. Increasingly, however, and over the last 10 years, more and more patients are being referred for the PVE, by vascular surgeons and other phlebologists, with pelvic venous reflux communicating with lower limb varicosities, and felt to be a significant or indeed the only cause of these veins.

Lower limb varicosities are typically associated with variable incompetence of the greater and lesser saphenous veins occasionally with perforating vein dysfunction $[4,38]$.

Although surgery is effective in eliminating or reducing lower limb varicose veins, recurrent varices after surgery (REVAS) ranges between $20 \%$ and $80 \%$ of patients between 5 and 20 years after initial surgery, depending on the definition of recurrence $[4,35,38,27,50-54]$. 
The commonest explanation of varicose vein recurrence in the lower limbs is neovascularization [55]. However, a more likely explanation is the development of collateral veins between the pelvis and lower limbs. Indeed, this is supported by growing evidence that primary or adjunctive treatment by PVE allows for the successful treatment of symptomatic lower limb venous recurrences [43]. Such a collateral network of veins has previously been described [56] and may be demonstrated by catheter venography with incompetence confirmed by 'functional' duplex sonography. It has also been reported that no more than $45 \%$ of these recurrences occur in the region of the greater saphenous vein suggesting reflux from pelvic veins as the cause [57].

Furthermore, many studies have demonstrated lower limb varicosities partly or entirely of pelvic venous origin with the latter group having a competent saphenofemoral junction [58-63] and not confined to the perineal, gluteal or perianal tissues.

Minimally invasive imaging methods such as selective catheter venography [17] and non-invasive studies including duplex sonography $[3,5,6,64-66]$, computed tomography (CT) $[67,68]$ and magnetic resonance imaging (MRI) [69, 70] are most frequently used to assess pelvic and lower limb venous incompetence.

Selective venography has been considered the gold standard for demonstrating pelvic incompetence as it can potentially show communication between incompetent pelvic veins (ovarian and/or internal iliac) and lower limb varicosities, but a recent study cautions reliance on this modality [71]. However, as dilated and presumed incompetent veins have been described in asymptomatic parous women [2], a more functional assessment of pelvic venous incompetence may be required and transvaginal, transperineal or transrectal duplex sonography have been suggested to be such an investigation [5, 6]. Pre-operative assessment with functional imaging techniques not involving ionizing radiation such as ultrasound or MR venography in an 'upright scanner', is desirable and such techniques may be reproducible with appropriate training.

Although ultrasound is well suited to 'direct' therapeutic embolization to minimize financial and radiation 'costs' associated with unnecessarily embolizing non-refluxing veins, it is highly operator dependent. One advantage is its use in assessing the outcome of therapeutic embolotherapy in determining whether the procedure has been 'successful' in eliminating diagnosed reflux and identifying any new reflux prior to definitive 'pinhole' endovenous lower limb surgery.

Endovenous ablation of pelvic venous incompetence is a relatively simple, safe and efficacious technique for occluding and obliterating refluxing veins associated with pelvic venous congestion syndrome or implicated in the aetiology of de novo or recurrent lower limb venous varicosities with or without vulval or perivulvar veins. Conventional catheter techniques are used typically under conscious sedation employing commonly available occlusive agents including liquid sclerosants, glue, foam and most commonly platinum coils. The latter are highly visible and do not preclude patients undergoing future MRI imaging (although artefact is created on CT scanning). The procedure has a shallow learning curve and complications associated with therapeutic embolization are well defined, rare and easily managed percutaneously.

Conflict of interest None.

Disclosures The author is a Proctor for Cook Medical.

Open Access This article is distributed under the terms of the Creative Commons Attribution License which permits any use, distribution, and reproduction in any medium, provided the original author(s) and the source are credited.

\section{References}

1. Nascimento AB, Mitchell DG, Holland G (2002) Ovarian veins: magnetic resonance imaging findings in an asymptomatic population. J Magn Reson Imaging 15:551-556

2. Rozenblit A, Ricci Z, Tuvia J, Amis ES (2001) Incompetent and dilated ovarian vein: a common $\mathrm{CT}$ finding in asymptomatic parous women. Am J Roentgenol 176:119-122

3. Ganeshan A, Upponi S, Hon LQ, Uthappa MC, Warakaulle DR, Uberoi R (2007) Chronic pelvic pain due to pelvic congestion syndrome: the role of diagnostic and interventional radiology. Cardiovasc Interv Radiol 30(6):1105-1111

4. Meneses L, Fava M, Diaz P, Andia M, Tejos C, Irarrazabal P, Uribe S (2013) Embolization of incompetent pelvic veins for the treatment of recurrent varicose veins in lower limbs and pelvic congestion syndrome. Cardiovasc Interv Radiol 36:128-132

5. Marsh P, Holdsock J, Harrison C, Smith C, Price BA, Whiteley MS (2009) Pelvic vein reflux in female patients with varicose veins: comparison of incidence between a specialist private vein clinic and the vascular department of a National Health Service District General Hospital. Phlebology 24(3):108-113. doi:10. 1258/phleb.2008.008041

6. Francheschi C, Bahnini A (2005) Treatment of lower extremity venous insufficiency due to pelvic leak points in women. Ann Vasc Surg 19(2):284-288

7. Hobbs JT (1990) The pelvic congestion syndrome. Br J Hosp Med 43:200-206

8. Taylor HC (1949) Vascular congestion and hyperemia; their effects on structure and function in the female reproductive system. Am J Obstet Gynecol 57:637-653

9. Kölbel T, Lindh $M$, Akesson $M$, Wassèlius J, Gottsäter A, Ivancev K (2009) Chronic iliac vein occlusion: midterm results of endovascular recanalization. J Endovasc Ther 16:483-491

10. Scott TE, LaMorte WW, Gorin DR, Menzoian JO (1995) Risk factors for chronic venous insufficiency: a dual case-control study. J Vasc Surg 22:622-628

11. Khan SR, Ginsberg JS (2004) Relationship between deep venous thrombosis and the postthrombotic syndrome. Arch Intern Med 164:17-26

12. Whiteley AM, Taylor DC, Whiteley MS (2013) Pelvic venous reflux is a major contributory cause of recurrent varicose veins in more than a quarter of women. J Vasc Surg 1:100-101 
13. Perrin MR, Labropoulos N, Leon LR Jr (2006) Presentation of the patient with recurrent varices after surgery (REVAS). J Vasc Surg 43:327-334

14. Barber B, Horton A, Patel U (2012) Anatomy of the origin of the gonadal veins on CT. Anatomy of the origin of the gonadal veins on CT. J Vasc Interv Radiol 23(2):211-215

15. Ahlberg NE, Bartley O, Chidekel N (1966) Right and left gonadal veins: an anatomical and statistical study. Acta Radiol Diagn 4:593-601

16. Edwards RD, Robertson IR, MacLean AB, Hemmingway AP (1993) Case report: pelvic pain syndrome-successful treatment of a case by ovarian vein embolization. Clin Radiol 47:429-431

17. Kennedy A, Hemmingway A (1990) Radiology of ovarian varices. Br J Hosp Med 44:38-43

18. Raju S, Neglen P (2006) High prevalence of nonthrombotic iliac vein lesions in chronic venous disease: a permissive role in pathogenicity. J Vasc Surg 44(1):136-143

19. Scultetus AH, Villavicencio JL, Gillespie DL (2001) The nutcracker syndrome: its role in the pelvic venous disorders. J Vasc Surg 34:812-819

20. Hartung O, Grisoli D, Boufi M, Marani I, Hakam Z, Barthelemy P, Alimi YS (2005) Endovascular stenting in the treatment of pelvic vein congestion caused by nutcracker syndrome: lessons learned from the first five cases. J Vasc Surg 42(2):275-280

21. Asciutto G, Asciutto KC, Mumme A, Geier B (2009) Pelvic venous incompetence: reflux patterns and treatment results. Eur J Vasc Endovasc Surg 38:381-386

22. Scultetus AH, Villavicencio JL, Gillespie DL, Kao TC, Rich NM (2002) The pelvic venous syndromes: analysis of our experience with 57 patients. J Vasc Surg 36:881-888

23. Creton D, Hennequin L, Kohler F, Allaert FA (2007) Embolisation of symptomatic pelvic veins in women presenting with non-saphenous varicose veins of pelvic origin-three year follow-up. Eur J Vasc Endovasc Surg 34:112-117

24. Kim HS, Malhotra AD, Rowe PC, Lee JM, Venbrux AC (2006) Embolotherapy for pelvic congestion syndrome: long-term results. J Vasc Interv Radiol 17:289-297

25. Laborda A, Medrano J, de Blas I, Urtiaga I, Carnevale FC, de Gregorio MA (2013) Endovascular treatment of pelvic congestion syndrome: visual analogue scale (VAS) long-term follow up clinical evaluation in 202 patients. Cardiovasc Interv Radiol 36(4):1006-1014

26. Monedero JL, Zubicoa Ezpeleta S, Castro Castro J, Calderon Ortiz M, Sellars Fernandez G (2006) Embolization treatment of recurrent varices of pelvic origin. Phlebology 21(1):3-11

27. Ratnam LA, Marsh P, Holdstock JW, Harrison CS, Hussain FF, Whiteley MS, Lopez AJ (2008) Pelvic vein embolisation in the management of varicose veins. Cardiovasc Interv Radiol 31(6):1159-1164

28. Moyano CJL, Teba del Pino F, Arellano GR, Romero TJC, Albacete AP, Ruiz ZC, Pereira SI (1993) The ovarian vein syndrome. Its treatment by percutaneous embolisation and a review of the same. Arch Esp Urol 46:802-806

29. Capasso P, Simons C, Trotteur G, Donderlinger RF, Henroteaux D, Gaspard U (1997) Treatment of symptomatic pelvic varices by ovarian vein embolisation. Cardiovasc Interv Radiol 20:107-111

30. Cordts PR, Eclavea A, Buckley PJ, De Moiorilius CA, Cockerill ML, Yeager TD (1998) Pelvic congestion syndrome: early clinical results after transcatheter ovarian vein embolisation. J Vasc Surg 28:862-868

31. Maleux G, Stockx L, Wilms G, Marchal G (2000) Ovarian vein embolisation for the treatment of pelvic congestion syndrome: long-term technical and clinical results. J Vasc Interv Radiol 11(7):859-864

32. Lopez AJ, Holdstock J, Harrison C, Price B, Whiteley MS (2012) Transjugular pelvic vein embolization in the management of lower limb varicosities: experience gained in 1000 patients. Abstracts from Global Embolization Symposium and Technologies (May 3-6). www.jvir.org/article/S1051-0443(12)00205-9/pdf

33. Mathis BV, Miller JS, Lukens ML, Paluzzi MW (1995) Pelvic congestion syndrome: a new approach to an unusual problem. Am Surg 61:1016-1018

34. Boersma D, van Eekeren RR, Werson DA, van der Waal RI, Reijnen MM, de Vries JP (2013) Mechanochemical endovenous ablation of small saphenous vein insufficiency using the Clarivein ${ }^{\circledR}$ device: one year results of a prospective series. Eur J Vasc Endovasc Surg 45(3):299-303

35. Lawson J, Gauw S, van Vlijmen C, Pronk P, Gaastra M, Mooij M, Wittens CH (2013) Sapheon: the solution? Phlebology 28(Suppl 1):2-9

36. Tessari L, Cavezzi A, Frullini A (2001) Preliminary experience with a new sclerosing foam in the treatment of varicose veins. Dermatol Surg 27(1):58-60

37. Wang CL, Cohan RH, Ellis JH, Caoili EM, Wang G, Francis IR (2008) Frequency, outcome and appropriateness of treatment of non-ionic iodinated contrast media reactions. Am J Roentgenol 191(2):409-415

38. Marsh P, Holdstock JM, Bacon JL, Lopez AJ, Whiteley MS, Price BA (2008) Coil protruding into the common femoral vein following pelvic venous embolization. Cardiovasc Interv Radiol 31(2):435-438

39. Venbrux AC, Chang AH, Kim HS, Montague BJ, Hebert JB, Arepally A, Rowe PC, Barron DF, Lambert D, Robinson JC (2002) Pelvic congestion syndrome (pelvic venous incompetence): impact of ovarian and internal iliac vein embolotherapy on menstrual cycle and chronic pelvic pain. J Vasc Interv Radiol 13:171-178

40. Sichlau MJ, Yao JS, Vogelzang RL (1994) Transcatheter embolotherapy for the treatment of pelvic congestion syndrome. Obstet Gynecol 83:892-896

41. Tarazov PG, Prozorovskij KV, Ryzhkov VK (1997) Pelvic pain syndrome caused by ovarian varices: treatment by transcatheter embolization. Acta Radiol 38:1023-1025

42. Bachar GN, Belenky A, Greif F, Atar E, Gat Y, Itkin M, Verstanding A (2003) Initial experience with ovarian vein embolization for the treatment of chronic pelvic pain syndrome. Isr Med Assoc J 12:843-846

43. Pieri S, Agresti P, Morucci M, de'Medici L (2003) Percutaneous treatment of pelvic congestion syndrome. Radiol Med (Torino) 105:76-82

44. Kwon SH, Oh JH, Ko KR, Park HC, Huh JY (2003) Transcatheter ovarian vein embolization using coils for the treatment of pelvic congestion syndrome. Cardiovasc Interv Radiol 30:655-661

45. LePage PA, Villavicencio JL, Gomez ER, Sheridan MN, Rich NM (1991) The valvular anatomy of the iliac venous system and its clinical implications. J Vasc Surg 14:678-683

46. Chung MH, Huh CY (2003) Comparison of treatments for pelvic congestion syndrome. Tohoku J Exp Med 201:131-138

47. Beard RW, Highman JH, Pearce S, Reginald PW (1984) The diagnosis of pelvic varicosities in women with chronic pelvic pain. Lancet 2:946-949

48. Scultetus AH, Villavicencio JL, Rich NM (2003) The female pelvic venous syndrome-an overview. Phlebologie 32:37-42

49. Geier B, Barbera L, Mumme A, Koster O, Marpe B, Kaminsky C, Asciutto G (2007) Reflux patterns in the ovarian and hypogastric veins in patients with varicose veins and signs of pelvic venous incompetence. Chir Ital 59(4):481-488

50. Myers KA, Ziegenbein RW, Zeng GH, Matthews PG (1995) Duplex ultrasonography scanning for chronic venous disease: patterns of venous reflux. J Vasc Surg 21:605-612

51. Perrin MR, Guex JJ, Ruckley CV, dePalma RG, Royle JP, Eklof B, Nicolini P, Jantet G (2000) Recurrent varices after surgery (REVAS), a consensus document. Cardiovasc Surg 8:233-245 
52. Darke SG (1992) The morphology of recurrent varicose veins. Eur J Vasc Surg 6:512-517

53. Jones L, Braithwaite BD, Selwyn D, Cooke S, Earnshaw JJ (1996) Neovascularization is the principal cause of varicose vein recurrence; results of a randomized trial of stripping the long saphenous vein. Eur J Endovasc Surg 12:442-445

54. Fischer R, Linde N, Duff C, Jeanneret C, Chandler JG, Seeber P (2001) Late recurrent saphenofemoral junction reflux after ligation and stripping of the greater saphenous vein. J Vasc Surg 34:236-240

55. Labropoulos N, Delis K, Nicolaides AN, Leon M, Ramaswami G (1996) The role of the distribution and anatomic extent of reflux in the development of signs and symptoms in chronic venous insufficiency. J Vasc Surg 23:504-510

56. Moreau P (2005) Neovascularisation is not a major cause of varicose vein recurrence. Int J Angiol 11:99-101

57. Ndiaye A, Ndiaye A, Ndoye J, Diarra O, Diop M, Dia A, Ndiaye M, Sow ML (2006) The arch of the great saphenous vein: anatomical bases for failures and recurrences after surgical treatment of varices in the pelvic limb. About 54 dissections. Surg Radiol Anat 28(1):18-24

58. Vin F, Chleir F (1998) Echo Doppler classification of postoperative recurrence of varicose vein in the region of the internal saphenous vein. Presse Med 27(4):148-152

59. Massell TB, Heringman E, Greenstone SM (1966) Lower extremity varicosis originating from the pelvis. Angiology 17:121-126

60. Labropoulos N, Kang SS, Mansour MA, Giannoukas AD, Buckman J, Baker WH (1999) Primary superficial vein reflux with competent saphenous trunk. Eur J Vasc Endovasc Surg 18:201-206

61. Giannoukas AD, Dacie JE, Lumley JS (2000) Recurrent varicose veins of both lower limbs due to bilateral ovarian vein incompetence. Ann Vasc Surg 14:397-400

62. Labropoulos N, Tiongson J, Pryor L, Tassiopoulos AK, Kang SS, Mansour MA, Baker WH (2001) Nonsaphenous superficial vein reflux. J Vasc Surg 34:872-877
63. Seidel AC, Miranda F Jr, Juliano Y, Novo NF, dos Santos JH, de Souza DF (2004) Prevalence of varicose veins and venous anatomy in patients without truncal saphenous reflux. Eur J Vasc Endovasc Surg 28:387-390

64. Hobbs JT (2005) Varicose veins arising from the pelvis due to ovarian vein incompetence. Int J Clin Pract 59:1195-1203

65. Welch HJ, Faliakou EC, McLaughlin RL, Umphrey SE, Belkin M, O'Donnell TF Jr (1992) Comparison of descending phlebography with quantitative plethysmography, and duplex quantitative valve closure time in assessing deep venous reflux. J Vasc Surg 16:913-919

66. Neglen P, Raju S (1992) A comparison between descending phlebography and duplex Doppler investigation in the evaluation of reflux in chronic venous insufficiency: a challenge to phlebography as the "gold standard". J Vasc Surg 16:687-693

67. Caggiati A, Ricci S, Laghi A, Luccichenti P, Ravone P (2001) Three-dimensional contrastless varicography by spiral computed tomography. Eur J Vasc Endovasc Surg 21:374-376

68. Uhl JF, Verdeille S, Martin-Bouyer Y (2003) Three dimensional spiral CT venography for the pre-operative assessment of varicose patients. Vasa 32:91-94

69. Muller MA, Mayer D, Seifert B, Marincek B, Willmann JK (2008) Recurrent lower limb varicose veins: effect of direct contrast-enhanced three dimensional MR venographic findings on diagnostic thinking and therapeutic decisions. Radiology 247(3):887-895

70. Asciutto G, Mumme A, Marpe B, Köster O, Asciutto KC, Geier B (2008) MR venography in the detection of pelvic venous congestion. Eur J Endovasc Surg 36(4):491-496

71. Dos Santos SJ, Holdstock JM, Harrison CC, Lopez AJ, Whiteley MS (2014) Ovarian vein diameter cannot be used as an indicator of ovarian vein reflux. Eur J Vasc Endovasc Surg 49:90-94 